\title{
Effect of travoprost on 24-hour intraocular pressure in normal tension glaucoma
}

This article was published in the following Dove Press journal:

Clinical Ophthalmology

22 July 2010

Number of times this article has been viewed

Yuya Nomura'

Shunsuke Nakakura ${ }^{2}$

Mitsuyasu Moriwaki'

Yasuhiro Takahashi'

Kunihiko Shiraki'

'Department of Ophthalmology and Visual Sciences, Graduate School of Medicine, Osaka City University, Japan; ${ }^{2}$ Department of Ophthalmology,

Saiseikai Gose Hospital, Japan
Correspondence: Shunsuke Nakakura Department of Ophthalmology, Saiseikai Gose Hospital, 20 Oaza Mimuro, Gose 639-2306, Japan

$\mathrm{Tel}+8 \mathrm{I} 745623585$

Fax +8I 745632335

Email shunsukenakakura@yahoo.co.jp
Purpose: The effect of travoprost $0.004 \%$ on 24 -hour intraocular pressure (IOP) was examined in patients with normal tension glaucoma (NTG).

Subjects and methods: This study included 17 patients with newly diagnosed unilateral NTG. IOP was measured at three-hour intervals over 24 hours by Goldman applanation tonometer in patients taking topical travoprost $0.004 \%$ and was compared retrospectively with 24 -hour IOP data in untreated eyes.

Results: IOP values were significantly reduced at individual time points after treatment $(P<0.01)$. Mean 24-hour IOP, maximum 24-hour IOP, minimum 24-hour IOP, and 24-hour IOP fluctuations at baseline (mean $\pm \mathrm{SD}$ ) were $12.9 \pm 2.2 \mathrm{mmHg}, 15.4 \pm 2.7 \mathrm{mmHg}, 10.5 \pm 2.2 \mathrm{mmHg}$, and $4.9 \pm 1.2 \mathrm{mmHg}$, respectively, and were significantly reduced to $10.3 \pm 2.0 \mathrm{mmHg}$, $12.4 \pm 2.5 \mathrm{mmHg}, 8.5 \pm 1.9 \mathrm{mmHg}$ (all $P<0.001)$, and $3.9 \pm 1.5 \mathrm{mmHg}(P<0.05)$, respectively, after treatment. The rate of IOP reduction greater than $20 \%$ was $58.8 \%$ (10 eyes) for maximum 24-hour IOP and 53.0\% (nine eyes) for mean 24-hour IOP.

Conclusion: Travoprost reduced IOP throughout the 24-hour study period, with over half of the eyes examined showing IOP reduction exceeding $20 \%$.

Keywords: 24-hour intraocular pressure, fluctuation, normal tension glaucoma, travoprost, Travatan Z

\section{Introduction}

Elevated intraocular pressure (IOP) is a primary risk factor for the development of glaucoma. However, some patients develop glaucomatous damage to the optic nerve in the absence of elevated IOP, known as normal tension glaucoma (NTG). The importance of lowering IOP to reduce the progression of glaucomatous damage was demonstrated by the Collaborative Normal Tension Glaucoma (CNTG) study group which showed that lowering IOP by $30 \%$ from baseline reduces the risk of progression of visual field loss in NTG patients. However, $12 \%$ of treated patients progressed during five years of follow-up versus $35 \%$ of an untreated group. ${ }^{1,2}$

The Early Manifest Glaucoma Trial (EMGT) indicated that IOP fluctuation is not a risk factor for the progression of glaucoma. ${ }^{3}$ However, some reports have shown that circadian IOP, diurnal IOP fluctuation, and maximum diurnal IOP are also important factors influencing the progression of glaucoma. ${ }^{4-6}$ IOP fluctuation remains a controversial issue that has not yet been resolved. However, present management of NTG involves achieving the best possible reduction in IOP over a 24-hour period.

Once patients begin to use antiglaucoma eye drops, their IOP curve is altered, and estimation of maximum IOP becomes difficult. Wilensky et $\mathrm{al}^{7}$ conducted a 
study of 24-hour IOP measured with a home tonometer in patients with well-controlled IOP and found that a half of the maximum IOP measurements were obtained outside of clinic hours. This study shows the importance of measuring IOP throughout a 24-hour period. ${ }^{7,8}$

Prostaglandin analogs can strongly reduce IOP compared with beta-blockers or carbonic anhydrase inhibitors..$^{9,10}$ Latanoprost $0.005 \%$ and bimatoprost $0.03 \%$, both prostaglandin analogs, are effective in reducing IOP in NTG patients. ${ }^{10-13}$ Another prostaglandin analog, travoprost $0.004 \%$, has been shown to be equivalent in the reduction of IOP in primary open angle glaucoma and ocular hypertension..$^{9,14-16}$ However, only two reports have investigated the effect of travoprost on NTG. ${ }^{17,18}$ Suh et $\mathrm{al}^{17}$ reported the effect of travoprost on clinic IOP measurements in patients with NTG over a 12-month period, and Ang et $\mathrm{al}^{18}$ reported the effect of travoprost on daytime IOP in NTG patients. Neither group measured changes in IOP overnight in NTG patients. To the best of our knowledge, the present study is the first to evaluate the effect of travoprost $0.004 \%$ on 24 -hour IOP in NTG patients.

\section{Subjects and methods}

The study group comprised 17 newly diagnosed patients with unilateral NTG treated with travoprost $0.004 \%$ in one eye for one to two months. The patients were admitted to Osaka City University Hospital between January 2008 and October 2008 to evaluate their 24-hour IOP whilst receiving topical travoprost $0.004 \%$.

All patients agreed to undergo 24-hour IOP measurements and signed informed consent forms in accordance with the Declaration of Helsinki. A complete slit examination, gonioscopic evaluation, and dilated fundus examination were performed by glaucoma specialists in the clinic. Visual acuity, visual field tests (Humphrey 30-2 or 24-2 SITA program, Humphrey Field Analyzer, Carl Zeiss Meditec, Dublin, CA), and measurement of central corneal thickness by specular microscope (SP-3000P, Topcon, Tokyo) were also conducted. A diagnosis of NTG was made if criteria were fulfilled for glaucomatous optic disc change, the presence of visual field defects typical of glaucoma, and both clinic and untreated 24-hour IOP were $<21 \mathrm{mmHg}$. Patients with congenital, secondary, or narrow angle glaucoma, ocular inflammation, a severe corneal disorder, or a history of ocular surgery were excluded.

During hospitalization, IOP was measured in patients in the sitting position with a Goldmann applanation tonometer at three-hour intervals from midnight to 9:00 am by the same doctor. Patients self-administered travoprost $0.004 \%$ to the treated eye at night in their usual manner. For nighttime measurements, patients were gently awakened and walked 10-20 meters to the tonometer. Immediately after IOP measurement, patients returned to their beds. Mean 24-hour IOP was determined as the mean of the eight IOP measurements recorded. Fluctuation in 24-hour IOP was calculated as the difference between maximum 24-hour IOP and minimum 24-hour IOP. Clinic IOP was measured between 10:00 am and 6:00 pm at approximately the same time for each patient.

We used Travatan $Z^{\mathrm{TM}}$ ophthalmic solution $0.004 \%$ (Alcon Japan Limited, Tokyo), which is the prostaglandin analog product without benzalkonium chloride (BAK) and which has a similar IOP reduction efficacy and safety profile as does travoprost with BAK. ${ }^{19}$ Each patient's 24-hour IOP data following administration of travoprost were retrospectively compared with their 24-hour IOP data obtained in the same manner from the same untreated eye at one to two months prior to treatment.

\section{Statistical analysis}

Values are shown as means \pm standard deviation (SD). We used the paired t-test to analyze the differences between IOP at individual time points before and after treatment for both eyes, maximum 24-hour IOP, minimum 24-hour IOP, clinic IOP, and 24-hour IOP fluctuation before and after treatment in the treated eye. Paired t-tests and post hoc testing (Bonferroni correction) were used to analyze differences between the different time points of each IOP curve (treated eye and fellow eye before and after treatment). A $P$ value of $<0.05$ was considered statistically significant.

\section{Results \\ Patients}

We included 17 newly diagnosed unilateral NTG patients in the present study (right eye, $n=6$; left eye, $n=11$ ). The patients comprised nine men and eight women with a mean age of $63.1 \pm 14.3$ (range 31-81) years. Average central corneal thickness for both eyes was $515.8 \pm 34.6 \mu \mathrm{M}$. Mean deviation was $-7.3 \pm 3.3 \mathrm{~dB}$ (range $-3.3-15.0$ ) in the treated eyes. Data for 24-hour IOP in both eyes are shown in Table 1. At all individual time points, IOP was significantly decreased after travoprost treatment in the treated eye $(P<0.01$, Figure 1$)$. There were no significant reductions in IOP at each time point in untreated fellow eyes $(P>0.05$, Figure 2$)$.

\section{Multiple comparisons between IOP curves}

Before treatment, there was a significant difference in IOP curves between 9:00 am and 12 pm, 12 pm and 9:00 pm, 
Table I Mean baseline and post-treatment IOP values

\begin{tabular}{llllll}
\hline & \multicolumn{2}{l}{ Treated eye } & & \multicolumn{2}{l}{ Untreated fellow eye } \\
\cline { 2 - 3 } \cline { 5 - 6 } & Baseline & Travoprost & & Before & After \\
\hline $9: 00 \mathrm{am}$ & $12.6 \pm 2.5$ & $10.4 \pm 1.9$ & & $11.9 \pm 2.2$ & $12.4 \pm 2.4$ \\
$12: 00 \mathrm{pm}$ & $14.5 \pm 2.6$ & $11.0 \pm 2.3$ & & $13.5 \pm 2.5$ & $13.5 \pm 2.9$ \\
$3: 00 \mathrm{pm}$ & $13.4 \pm 2.7$ & $10.4 \pm 2.2$ & & $12.5 \pm 2.6$ & $12.5 \pm 2.7$ \\
$6: 00 \mathrm{pm}$ & $13.7 \pm 2.6$ & $10.3 \pm 2.0$ & & $12.7 \pm 2.4$ & $12.8 \pm 2.4$ \\
$9: 00 \mathrm{pm}$ & $12.0 \pm 2.4$ & $9.4 \pm 2.6$ & & $11.5 \pm 2.0$ & $11.4 \pm 2.7$ \\
$12: 00 \mathrm{am}$ & $12.2 \pm 3.2$ & $10.41 \pm 2.9$ & & $11.8 \pm 2.3$ & $11.9 \pm 2.9$ \\
$3: 00 \mathrm{am}$ & $12.5 \pm 3.4$ & $10.3 \pm 2.8$ & & $12.1 \pm 2.6$ & $11.3 \pm 2.8$ \\
$6: 00 \mathrm{am}$ & $12.8 \pm 2.2$ & $10.5 \pm 2.4$ & & $12.2 \pm 2.6$ & $11.5 \pm 2.7$ \\
\hline
\end{tabular}

Values indicate mean $\mathrm{mmHg} \pm \mathrm{SD}$.

Abbreviations: IOP, intraocular pressure; SD, standard deviation.

12:00 pm and 12:00 am, and 12:00 pm and 3:00 am in the treated eye, and between 12:00 pm and 9:00 pm and 12:00 pm and 12:00 am in the untreated eye. After treatment, there was no significant difference in IOP curves between these times in the treated eyes. However, there was a significant difference in IOP curves between 12:00 pm and 12:00 am, 12:00 pm and 3:00 am, and 12:00 pm and 6:00 am in the untreated eye.

Clinic IOP was reduced by $24.3 \%$ (from $14.8 \pm 2.7 \mathrm{mmHg}$ to $11.2 \pm 2.4 \mathrm{mmHg}, P<0.001)$. Mean 24 -hour IOP was reduced by $20.2 \%$ (from $12.9 \pm 2.2 \mathrm{mmHg}$ to $10.3 \pm 2.0 \mathrm{mmHg}$, $P<0.001$ ). Maximum 24-hour IOP decreased 19.5\% (from $15.4 \pm 2.7 \mathrm{mmHg}$ to $12.4 \pm 2.5 \mathrm{mmHg}, P<0.001)$, and minimum 24-hour IOP was reduced by $19.0 \%$ (from $10.5 \pm$ $2.2 \mathrm{mmHg}$ to $8.5 \pm 1.9 \mathrm{mmHg}, P<0.001)$. Fluctuation in 24-hour IOP was flattened by $20.4 \%$ (from $4.9 \pm 1.2 \mathrm{mmHg}$ to $3.9 \pm 1.5 \mathrm{mmHg}, P<0.05$, Table 2).

The percentage reduction of each parameter in the treated eye is shown in Table 3. The rate of $>30 \%$ reduction in maximum 24-hour IOP was $23.5 \%$ and in mean 24-hour
IOP was $11.8 \%$. The rate of $>20 \%$ reduction was $58.8 \%$ in maximum 24-hour IOP and 53.0\% in mean 24-hour IOP. Categorization as a travoprost nonresponder (TNR), defined as a mean 24 -hour IOP reduction $<10 \%$, occurred in two eyes $(11.8 \%)$. No serious treatment-related adverse events were observed in this study, and any adverse events that did occur were mild and controllable.

\section{Discussion}

The present study is the first to show the effect of travoprost on 24-hour IOP in NTG patients. In this study, the rate of IOP reduction was $20.2 \%$ for mean 24 -hour IOP, $19.5 \%$ for maximum 24-hour IOP, and $20.4 \%$ for 24 -hour IOP fluctuation. The results of this study indicate that travoprost can reduce IOP throughout a 24-hour period and flatten the IOP curve.

In the present study, travoprost reduced clinic IOP by $24.3 \%$. In previous studies, IOP reduction by latanoprost $0.005 \%$ and bimatoprost $0.03 \%$ in NTG has been reported to be in the range of $12.7 \%$ to $20 \%$ and $16 \%$ to $21.6 \%$, respectively. ${ }^{10,13,20,21}$ Travoprost $0.004 \%$ has been reported to have similar results ( $16.7 \%$ to $25.1 \%) .{ }^{17,18}$ Our results are in accordance with the results of these previous studies.

Ang et a $1^{18}$ published the only report showing the effect of travoprost on daytime IOP in NTG. These authors reported a mean IOP reduction of $16.1 \%$, a maximum IOP reduction of $13.5 \%$, a $43 \%$ rate of $>20 \%$ IOP reduction, and a $30 \%$ rate of $<10 \%$ IOP reduction (considered as TNR) in both mean and maximum IOP. These findings are considerably worse than our results. We suspect that this disparity may be due to measurement of daytime IOP only and that maximum and minimum IOP may have changed outside of daytime hours in the earlier study. ${ }^{7,8}$ Another possible explanation

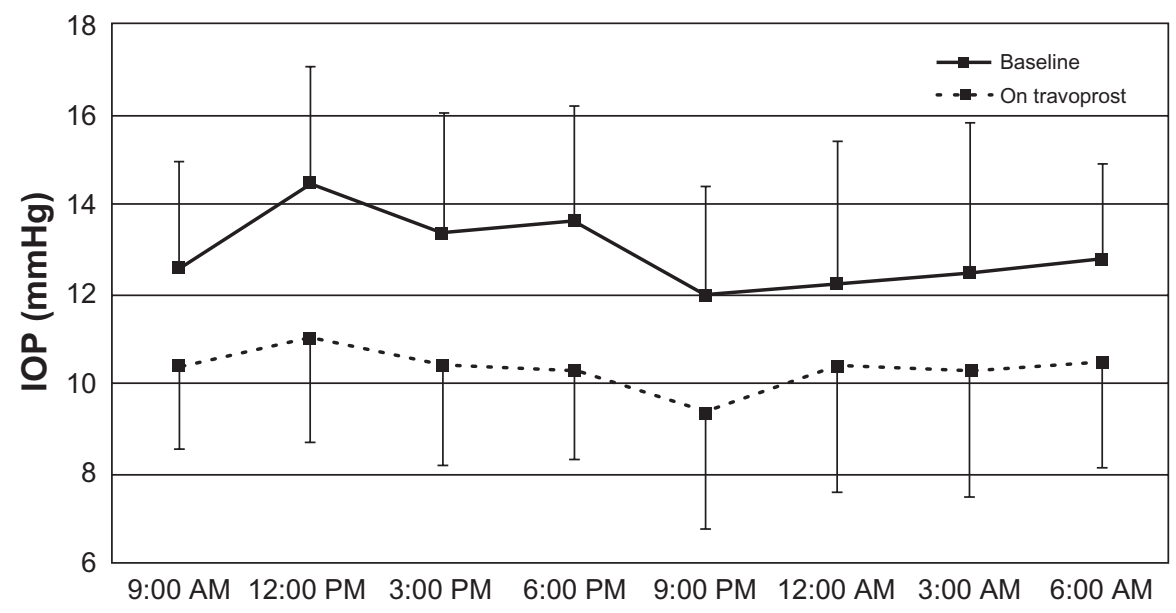

Figure I IOP measurements from the travoprost-treated eye over 24 hours. There is a significant reduction in IOP at each time point $(P<0.0 \mathrm{I})$. The 24 -hour IOP curve also shifted toward a lower IOP.

Abbreviation: IOP, intraocular pressure. 


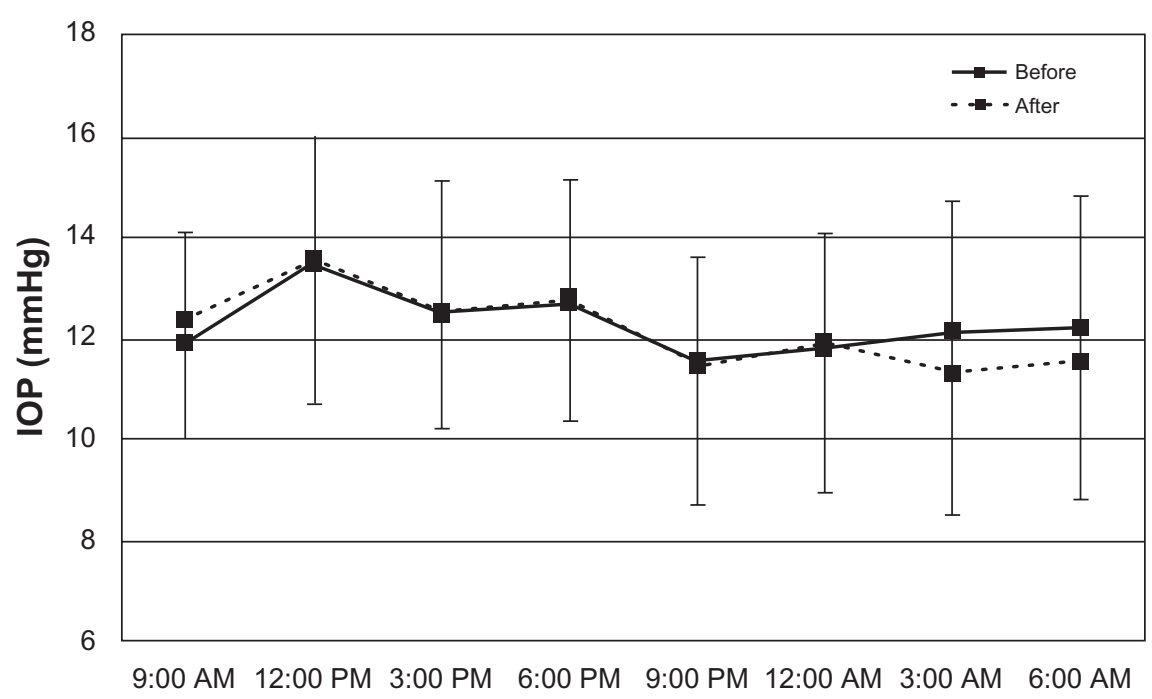

Figure 2 IOP measurements from the fellow eye over 24 hours. There is no significant IOP reduction at each time point $(P>0.05)$. Abbreviation: IOP, intraocular pressure.

is that the earlier investigators included both eyes in their study, which may have led to a TNR double-counting error. Additionally, $96 \%$ of their patients were Caucasians. Netland et $\mathrm{al}^{22}$ reported that travoprost is more effective in blacks than nonblacks, so patient race might influence this result. Furthermore, Suh et $\mathrm{al}^{17}$ reported the effect of travoprost $0.004 \%$ during 12 months of treatment and noted that IOP reduction was evident at one month; however, a slight increase in IOP occurred between nine and 12 months. Almost all of our data were obtained within a one- to twomonth period after the beginning of travoprost treatment, whereas the data from the study by Ang et al were obtained at six months. ${ }^{18}$

Achievement of an IOP reduction greater than $30 \%$ as recommended by the CNTG study group is very difficult using a single, topical antiglaucoma eye drop. ${ }^{10-13,17,18,20,21}$ In our study, the rates of $30 \%$ IOP reduction are $23.5 \%$ for maximum 24-hour IOP and $11.8 \%$ for mean 24 -hour IOP. When a topical combination therapy is needed to achieve the target reduction in IOP, travoprost without BAK is a superior option because preservatives such as BAK can induce conjunctival inflammation and affect success rates for filtering surgery. ${ }^{23,24}$
However, reduction of IOP alone is considered to be insufficient for the management of NTG. Hemodynamic factors such as ocular perfusion pressure (OPP) are also reported to be important. ${ }^{25-27}$ Among the topical antiglaucoma eye drops, the prostaglandin F2-alpha analogs (travoprost, latanoprost, and bimatoprost) and dorzolamide increase OPP, whereas timolol, a beta-blocker, and brimonidine do not. ${ }^{28-30}$ Therefore, to investigate the effect of eye drops, both the reduction in IOP and the hemodynamic effects of the medication should be evaluated.

The present study suggests that travoprost reduces IOP throughout a 24-hour period in NTG patients, and an IOP reduction greater than $20 \%$ was observed in over half of the eyes examined. However, our study reported shortterm results in a small group of patients in whom IOP was measured during only one 24-hour period, and we compared these results retrospectively with untreated 24-hour IOP measurements made one to two months earlier, prior to the started of travoprost. Further long-term, large-scale, prospective studies are needed to compare our findings with the effects of other prostaglandin analogs on 24-hour IOP in NTG.

Table 2 Changes in IOP and percentage change from baseline in the treated eye

\begin{tabular}{lllll}
\hline & Travoprost & Baseline & IOP reduction (\%) & P value \\
\hline Clinic IOP & $11.2 \pm 2.4$ & $14.8 \pm 2.7$ & $24.3 \%$ & $<0.001$ \\
Mean 24-hour IOP & $10.3 \pm 2.0$ & $12.9 \pm 2.2$ & $20.2 \%$ & $<0.001$ \\
Maximum 24-hour IOP & $12.4 \pm 2.5$ & $15.4 \pm 2.7$ & $19.5 \%$ & $<0.001$ \\
Minimum 24-hour IOP & $8.5 \pm 1.9$ & $10.5 \pm 2.2$ & $19.0 \%$ & $<0.001$ \\
24-hour IOP fluctuation & $3.9 \pm 1.5$ & $4.9 \pm 1.2$ & $20.4 \%$ & $<0.05$ \\
\hline
\end{tabular}

Values indicate mean $\mathrm{mmHg} \pm \mathrm{SD}$.

Abbreviations: IOP, intraocular pressure; SD, standard deviation. 
Table 3 Distribution of percentage change from baseline in the treated eye

\begin{tabular}{lllll}
\hline & $\geqq 30 \%$ & $\mathbf{2 0} \%-\mathbf{2 9 . 9 \%}$ & $\mathbf{1 0 \% - 1 9 . 9 \%}$ & $\mathbf{0 \% - 9 . 9 \%}$ \\
\hline Clinic IOP & $23.5 \%$ & $41.2 \%$ & $23.5 \%$ & $11.8 \%$ \\
Mean 24-hour IOP & $11.8 \%$ & $41.2 \%$ & $35.3 \%$ & $11.8 \%$ \\
Maximum 24-hour IOP & $23.5 \%$ & $35.3 \%$ & $17.6 \%$ & $23.5 \%$ \\
Minimum 24-hour IOP & $23.5 \%$ & $17.6 \%$ & $29.4 \%$ & $29.4 \%$ \\
\hline
\end{tabular}

Abbreviation: IOP, intraocular pressure.

\section{Acknowledgments/disclosures}

The authors have no financial interest in this study, and report no other conflicts of interest in this work.

\section{References}

1. Collaborative Normal Tension Glaucoma Study Group. Comparison of glaucomatous progression between untreated patients with normaltension glaucoma and patients with therapeutically reduced intraocular pressures. Am J Ophthalmol. 1998;126(4):487-497.

2. Collaborative Normal Tension Glaucoma Study Group. The effectiveness of intraocular pressure reduction in the treatment of normal-tension glaucoma. Am J Ophthalmol. 1998;126(4):498-505.

3. Bengtsson B, Leske MC, Hyman L, Heijl A; Early Manifest Glaucoma Trial Group. Fluctuation of intraocular pressure and glaucoma progression in the early manifest glaucoma trial. Ophthalmology. 2007;114(2):205-209.

4. Asrani S, Zeimer R, Wilensky J, Gieser D, Vitale S, Lindenmuth K. Large diurnal fluctuations in intraocular pressure are an independent risk factor in patients with glaucoma. J Glaucoma. 2000;9(2):134-142.

5. Ishida K, Yamamoto T, Kitazawa Y. Clinical factors associated with progression of normal-tension glaucoma. J Glaucoma. 1998;7(6):372-377.

6. Zeimer RC, Wilensky JT, Gieser DK, Viana MA. Association between intraocular pressure peaks and progression of visual field loss. Ophthalmology. 1991;98(1):64-69.

7. Wilensky JT, Gieser DK, Mori MT, Langenberg PW, Zeimer RC. Selftonometry to manage patients with glaucoma and apparently controlled intraocular pressure. Arch Ophthalmol. 1987;105(8):1072-1075.

8. Nakakura S, Nomura Y, Ataka S, Shiraki K. Relation between office intraocular pressure and 24-hour intraocular pressure in patients with primary open-angle glaucoma treated with a combination of topical anti-glaucoma eye drops. J Glaucoma. 2007;16(2):201-204.

9. Stewart WC, Konstas AG, Nelson LA, Kruft B. Meta-analysis of 24-hour intraocular pressure studies evaluating the efficacy of glaucoma medicines. Ophthalmology. 2008;115(7):1117-1122.

10. Cheng JW, Cai JP, Wei RL. Meta-analysis of medical intervention for normal tension glaucoma. Ophthalmology. 2009;116(7):1243-1249.

11. Ang A, Reddy MA, Shepstone L, Broadway DC. Long term effect of latanoprost on intraocular pressure in normal tension glaucoma. $\mathrm{Br} J$ Ophthalmol. 2004;88(5):630-634.

12. Ishibashi S, Hirose N, Tawara A, Kubota T. Effect of latanoprost on the diurnal variations in the intraocular and ocular perfusion pressure in normal tension glaucoma. J Glaucoma. 2006;15(5):354-357.

13. Dirks MS, Noecker RJ, Earl M, Roh S, Silverstein SM, Williams RD. A 3-month clinical trial comparing the IOP-lowering efficacy of bimatoprost and latanoprost in patients with normal-tension glaucoma. Adv Ther. 2006;23(3):385-394.

Clinical Ophthalmology

\section{Publish your work in this journal}

Clinical Ophthalmology is an international, peer-reviewed journal covering all subspecialties within ophthalmology. Key topics include: Optometry; Visual science; Pharmacology and drug therapy in eye diseases; Basic Sciences; Primary and Secondary eye care; Patient Safety and Quality of Care Improvements. This journal is indexed on Submit your manuscript here: http://www.dovepress.com/clinical-ophthalmology-journal
14. Orzalesi N, Rossetti L, Bottoli A, Fogagnolo P. Comparison of the effects of latanoprost, travoprost, and bimatoprost on circadian intraocular pressure in patients with glaucoma or ocular hypertention. Ophthalmology. 2006;113(2):239-246.

15. Parrish RK, Palmberg P, Sheu WP; XLT study group. A comparison of latanoprost, bimatoprost, and travoprost in patients with elevated intraocular pressure: A 12-week, randomized, masked-evaluator multicenter study. Am J Ophthalmol. 2003;135(5):688-703.

16. Yildirim N, Sahin A, Gultekin S. The effect of latanoprost, bimatoprost, and travoprost on circadian variation of intraocular pressure in patients with open-angle glaucoma. J Glaucoma. 2008;17(1):36-39.

17. Suh MH, Park KH, Kim DM. Effect of travoprost on intraocular pressure during 12 months of treatment for normal-tension glaucoma. Jpn J Ophthalmol. 2009;53(1):18-23.

18. Ang GS, Kersey JP, Shepstone L, Broadway DC. The effect of travoprost on daytime intraocular pressure in normal tension glaucoma: A randomised control trial. Br J Ophthalmol. 2008;92(8):1129-1133.

19. Gross RL, Peace JH, Smith SE, et al. Duration of IOP reduction with travoprost BAK-free solution. J Glaucoma. 2008;17(3):217-222.

20. Rulo AH, Greve EL, Geijssen HC, Hoyng PF. Reduction of intraocular pressure with treatment of latanoprost once daily in patients with normal-pressure glaucoma. Ophthalmology. 1996;103(8):1276-1282.

21. Quaranta L, Pizzolante T, Riva I, Haidich AB, Konstas AG, Stewart WC. Twenty-four-hour intraocular pressure and blood pressure levels with bimatoprost versus latanoprost in patients with normaltension glaucoma. Br J Ophthalmol. 2008;92(9):1227-1231.

22. Netland PA, Robertson SM, Sullivan EK, et al; Travoprost Study Groups. Response to travoprost in black and nonblack patients with open-angle glaucoma or ocular hypertention. Adv Ther. 2003;20(3):149-163.

23. Noecker RJ, Herrygers LA, Anwaruddin R. Corneal and conjunctival changes caused by commonly used glaucoma medications. Cornea. 2004;23(5):490-496.

24. Broadway DC, Grierson I, O'Brien C, Hitchings RA. Adverse effects of topical antiglaucoma medication. II. The outcome of filtration surgery. Arch Ophthalmol. 1994;112(11):1446-1454.

25. Sung KR, Lee S, Park SB, et al. Twenty-four hour ocular perfusion pressure fluctuation and risk of normal-tension glaucoma progression. Invest Ophthalmol Vis Sci. 2009;50(11):5266-5274.

26. Choi J, Kim KH, Jeong J, Cho HS, Lee CH, Kook MS. Circadian fluctuation of mean ocular perfusion pressure is a consistent risk factor for normal-tension glaucoma. Invest Ophthalmol Vis Sci. 2007;48(1):104-111

27. Choi J, Jeong J, Cho HS, Kook MS. Effect of nocturnal blood pressure reduction on circadian fluctuation of mean ocular perfusion pressure: A risk factor for normal tension glaucoma. Invest Ophthalmol Vis Sci. 2006;47(3):831-836.

28. Costagliola C, Parmeggiani F, Virgili G, et al. Circadian changes of intraocular pressure and ocular perfusion pressure after timolol or latanoprost in Caucasians with normal-tension glaucoma. Graefes Arch Clin Exp Ophthalmol. 2008;246(3):389-396.

29. Koz OG, Ozsoy A, Yarangumeli A, Kose SK, Kural G. Comparison of the effects of travoprost, latanoprost and bimatoprost on ocular circulation: A 6-month clinical trial. Acta Ophthalmol Scand. 2007;85(8):838-843.

30. Quaranta L, Gandolfo F, Turano R, et al. Effects of topical hypotensive drugs on circulation IOP, blood pressure, amd calculated diastolic ocular perfusion pressure in patients with glaucoma. Invest Ophthalmol Vis Sci. 2006;47(7):2917-2923.

\section{Dovepress}

PubMed Central and CAS, and is the official journal of The Society of Clinical Ophthalmology (SCO). The manuscript management system is completely online and includes a very quick and fair peer-review system, which is all easy to use. Visit http://www.dovepress.com/ testimonials.php to read real quotes from published authors. 